\title{
Effect of an Organic Inhibitor on the Electrical Properties of High Carbon Steel in Simulated Acid Environment
}

\author{
Osarolube Eziaku \\ Department of Physics, University of Port Harcourt, Port Harcourt, Nigeria \\ Email: Eziaku68@yahoo.com
}

Received 9 April 2014; revised 8 May 2014; accepted 7 June 2014

Copyright @ 2014 by author and Scientific Research Publishing Inc.

This work is licensed under the Creative Commons Attribution International License (CC BY).

http://creativecommons.org/licenses/by/4.0/

(c) (i) Open Access

\begin{abstract}
The effect of 1-Phenyl-3-Methyl Pyrazol-5-one (HPMP) on the electrical properties of high carbon steel in Hydrochloric acid (HCI), Trioxonitrate (v) acid $\left(\mathrm{HNO}_{3}\right)$ and Perchloric acid $\left(\mathrm{HCIO}_{4}\right)$ was studied by weight loss method. The acidic medium caused a complete degradation of the electrical properties of the coated and uncoated high carbon steel. However, the attack was more on the uncoated coupons, which showed that HPHP is an effective corrosion inhibitor. $\mathrm{HNO}_{3}$ had the most severe effect on the metal. The coupons coated with HPMP generally had higher values of resistance $(0.0155 \Omega)$ and conductivity $(6.20 \mathrm{mho} / \mathrm{m})$ in $\mathrm{HCI}$ environment than the uncoated coupons $(0.0043 \Omega)$ and $(1.72 \mathrm{mho} / \mathrm{m})$. Similar results were obtained for $\mathrm{HNO}_{3}$ and $\mathrm{HCIO}_{4}$ environments. These values are lower than the values obtained for as-received coupons: -0.0466 and $8.64 \mathrm{mho} / \mathrm{m}$ respectively.
\end{abstract}

\section{Keywords}

Electrical Properties, Corrosion, High Carbon Steel, 1-Phenyl-3-Methyl Pyrazol-5-One

\section{Introduction}

Steel is one of the most important construction metals in the world. While this is common knowledge, many people do not understand the difference between high carbon steel and other types of steel. High carbon steel is any type of steel that contains over $0.8 \%$ of carbon but less than $2.11 \%$ of carbon in its composition. It has a reputation for being especially hard, less formable and machinable, but the extra carbon makes it more brittle than the other types of steel.

High carbon steel has many advantages over other options. It is excellent for making cutting tools such as 
knives, saws, drill bits, farming and gardening equipment, compression springs, high ware applications, wood cutting tools and high strength wire [1].

The failure of steel equipment due to acid corrosion in industries is widely reported, and the use of chemical inhibitors for steel corrosion has been established to be the most practical and cost effective means of controlling corrosion [2]-[4]. The extent of corrosion of metals among other factors depends on the nature of the material used, the environment that the equipment is introduced to and the control measures used. Several Nitrogen and Sulphur containing organic compounds have been used as corrosion inhibitors [5]-[8]. Corrosion inhibition is a surface process which involves the specific adsorption of the organic compounds on the metal surface [9]. The adsorbed inhibitor then acts as a retardant to cathodic and anodic electrochemical process of the corrosion.

Electrical properties of metals are usually affected when corrosion occurs. Since corrosion affects the dimensions or area of a material, one would infer that changes could occur in the electrical properties of the material due to corrosion effect. This paper reports the effect of 1-Phenyl-3-Methyl Pyrazol-5-one (HPMP) on the electrical properties of high carbon steel in various concentrations of $\mathrm{HCI}, \mathrm{HNO}_{3}$ and $\mathrm{HCIO}_{4}$.

\section{Materials and Methods}

The high carbon steel strip was mechanically pressed cut into coupons of dimension $4.0 \mathrm{~cm} \times 2.5 \mathrm{~cm} \times 1.0 \mathrm{~cm}$. Each coupon polished and drilled at one end, was degreased in ethanol, dried in acetone and preserved in a desiccator. Solutions were prepared using analar reagents and distilled water. The HPMP Inhibitor was synthesized as described by Vogel [10]. The coupons were coated with the inhibitor by completely immersing them in a mixture of ethanol and distilled water with 0.05M HPMP added to it. The coupons were retrieved after 1 hour, blow dried and reweighed immediately to determine the mass of the film.

The three categories of coupons, namely: The as-received (control coupons, that were not exposed to the acid medium), coated (coupons coated with HPMP inhibitor before exposure to the acid environment) and uncoated (coupons that were exposed to the acidic medium without the HPMP inhibitor) coupons, were all subjected to the current voltage measurement before and after the weight loss experiment.

\section{Results and Discussion}

The results from Table 1, show that HPMP inhibited High carbon steel in Hydrochloric acid and Nitric acid environments. The coated coupons had better corrosion resistance than the uncoated coupons. This is shown by the lower values of weight loss recorded for the coated coupons. The coupons went into solution in Nitric acid at a faster rate than in hydrochloric acid. This could be as a result of the nature of Nitric acid, as it is known to be a strong oxidizing agent, and so it oxidizes the iron in high carbon steel at a faster rate.

However, it was observed that the coated coupons in perchloric acid environment had higher values of weight loss than the uncoated coupons. This signifies that the inhibitor coating on the coupons was not stable and therefore dissolved, thereby aiding the corrosion of the coupons in perchloric acid. This behavior is attributed to

\section{Table 1. Weight loss (g) of coated and uncoated coupons in $0.8 \mathrm{M}$ concentration of different acid environments.}

\begin{tabular}{|c|c|c|c|c|c|c|}
\hline \multirow{2}{*}{$\begin{array}{c}\text { Time } \\
\text { (Days) }\end{array}$} & \multicolumn{2}{|c|}{ HCI } & \multicolumn{2}{|c|}{$\mathrm{HNO}_{3}$} & \multicolumn{2}{|c|}{$\mathrm{HCLO}_{4}$} \\
\hline & Uncoated coupon & Coated coupon & Uncoated coupon & Coated coupon & Uncoated coupon & Coated coupon \\
\hline 1 & 1.3154 & 1.1484 & 0.6189 & 0.4594 & 1.0085 & 1.0003 \\
\hline 3 & 1.5146 & 1.3557 & 1.0785 & 0.8338 & 1.0340 & 1.0460 \\
\hline 4 & 1.5309 & 1.4266 & 1.2789 & 1.0353 & 1.0430 & 1.0920 \\
\hline 5 & 1.5481 & 1.4697 & 1.5319 & 1.3353 & 1.0516 & 1.1482 \\
\hline
\end{tabular}


the fact that perchloric acid is one of the strongest acids known [11]. It is a powerful oxidizing agent and thus causes fast dissolution of the coupons. It was also observed that the weight loss increased with increase in exposure time for both uncoated and coated coupons.

Like all metals, steel can conduct electricity. The three main electrical properties of steel include its electrical conductivity, electrical resistivity and temperature co-efficient. Electrical conductivity is the ability of a material to conduct an electrical charge over a certain distance, while resistivity is the reciprocal of conductivity. The I-V characteristics of high carbon steel in different concentrations of the acidic medium are shown on Figure 1. The as-received coupon recorded higher current than those that were exposed to various concentrations of the acidic medium. The acidic medium caused a complete degradation of the electrical properties of both the coated and uncoated coupons, as shown in Table 2. There was a general decrease in the current flowing through the metal, when compared with that of the as-received coupons. The coated coupons recorded higher current flow than the uncoated coupons. The plots are shown on Figure 2.

Although there was a remarkable decrease in the I-V characteristics of the coupons exposed to the acid environment, the normal Ohmic behavior, which is usually associated with metallic conductors still maintained. That is, the exposed coupons were observed to exhibit the normal linearity variation pattern typical of electrical conducting materials as shown in Figure 1. Similar results were obtained by Owate et al., Brikby et al., and Darry and spear [12]-[14].

Table 3 shows the resistance and conductivity of high carbon steel in various concentrations of the acids. Both parameters were seen to decrease with increasing concentration. This result is in agreement with earlier researchers [13] [15]. Table 4 shows the resistance and conductivity of the coated and uncoated coupons in the

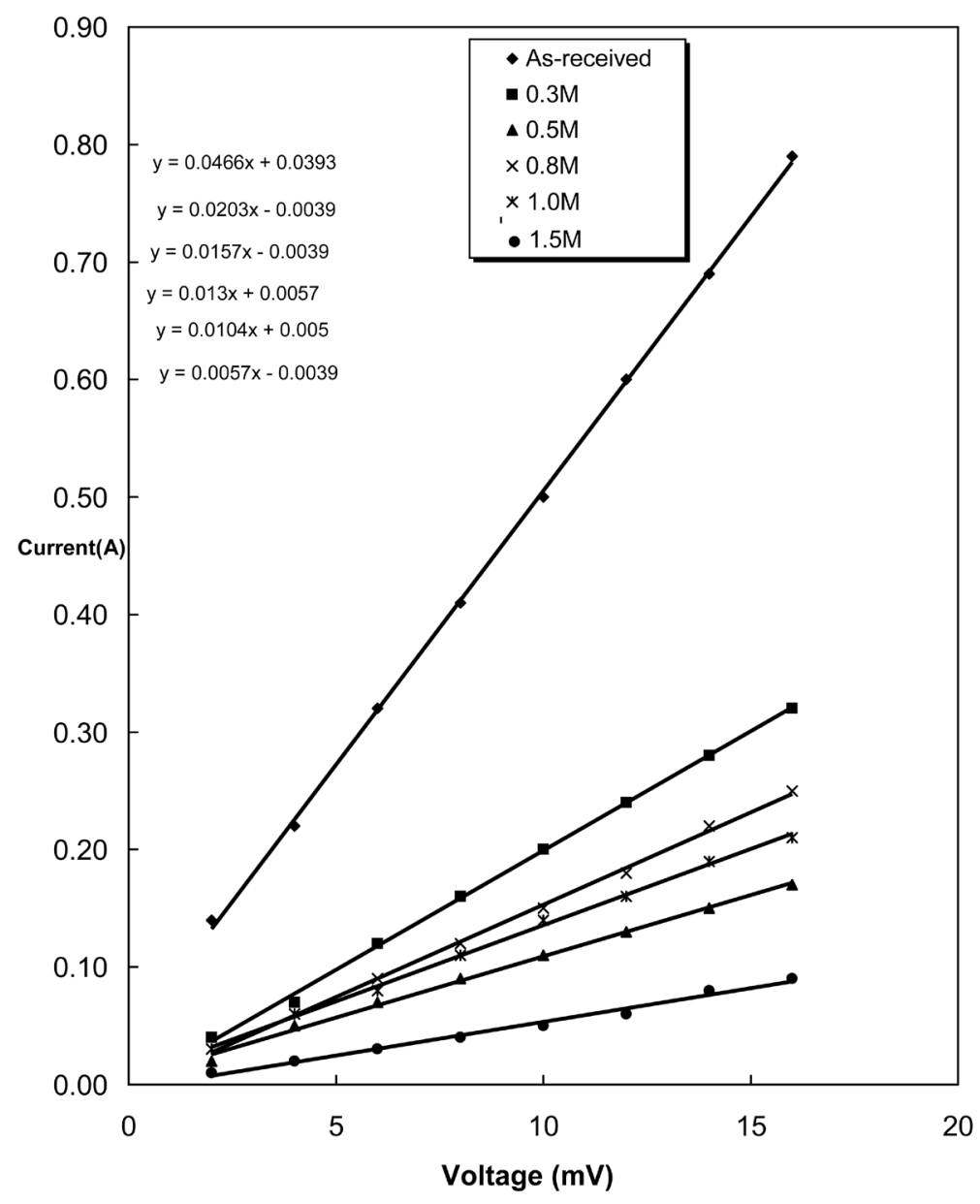

Figure 1. I-V Characteristics of uncoated high carbon steel in different concentrations of $\mathrm{HCLO}_{4}$. 




Figure 2. I-V Characteristic of high carbon steel coupons in $\mathrm{HCl}, \mathrm{HNO}_{3}, \mathrm{HClO}_{4}$.

Table 2. I-V characteristics of high carbon steel coupons in $\mathrm{HCl}, \mathrm{HNO}_{3}$ and $\mathrm{HCIO}_{4}$.

\begin{tabular}{|c|c|c|c|c|c|c|c|}
\hline \multirow{3}{*}{$\begin{array}{l}\text { Voltage } \\
(\mathrm{mV})\end{array}$} & \multicolumn{7}{|c|}{ Current (A) } \\
\hline & \multirow{2}{*}{$\begin{array}{l}\text { As Received } \\
\text { coupons }\end{array}$} & \multicolumn{2}{|c|}{$\mathrm{HCl}$} & \multicolumn{2}{|c|}{$\mathrm{HNO}_{3}$} & \multicolumn{2}{|c|}{$\mathrm{HClO}_{4}$} \\
\hline & & $\begin{array}{l}\text { Uncoated } \\
\text { coupons }\end{array}$ & $\begin{array}{c}\text { Coated } \\
\text { coupons }\end{array}$ & $\begin{array}{l}\text { Uncoated } \\
\text { coupons }\end{array}$ & $\begin{array}{c}\text { Coated } \\
\text { coupons }\end{array}$ & $\begin{array}{l}\text { Uncoated } \\
\text { coupons }\end{array}$ & $\begin{array}{l}\text { Coated } \\
\text { coupons }\end{array}$ \\
\hline 2 & 0.14 & 0.00 & 0.05 & 0.00 & 0.00 & 0.02 & 0.02 \\
\hline 4 & 0.22 & 0.02 & 0.07 & 0.00 & 0.02 & 0.03 & 0.05 \\
\hline 6 & 0.32 & 0.03 & 0.10 & 0.01 & 0.03 & 0.05 & 0.07 \\
\hline 8 & 0.41 & 0.03 & 0.15 & 0.01 & 0.05 & 0.07 & 0.10 \\
\hline 10 & 0.50 & 0.05 & 0.17 & 0.02 & 0.07 & 0.07 & 0.10 \\
\hline 12 & 0.60 & 0.05 & 0.20 & 0.02 & 0.10 & 0.10 & 0.12 \\
\hline 14 & 0.69 & 0.05 & 0.22 & 0.03 & 0.10 & 0.10 & 0.15 \\
\hline 16 & 0.79 & 0.07 & 0.27 & 0.03 & 0.13 & 0.12 & 0.20 \\
\hline
\end{tabular}


Table 3. Resistance $(\Omega)$ and conductivity $(\mathrm{mho} / \mathrm{m})$ of coupons in various concentrations of the acids.

\begin{tabular}{|c|c|c|c|c|c|c|c|}
\hline & \multirow{3}{*}{ Conc. (M) } & \multicolumn{6}{|c|}{ ACID } \\
\hline & & \multicolumn{2}{|r|}{$\mathrm{HCl}$} & \multicolumn{2}{|c|}{$\mathrm{HNO}_{3}$} & \multicolumn{2}{|r|}{$\mathrm{HClO}_{4}$} \\
\hline & & $\mathbf{R}(\Omega)$ & $\mathrm{K} \times 10^{-3}(\mathrm{mho} / \mathrm{m})$ & $\mathbf{R}(\mathbf{\Omega})$ & $\mathrm{K} \times 10^{-3}$ & $\mathbf{R}(\mathbf{\Omega})$ & $\mathrm{K} \times 10^{-3}(\mathrm{mho} / \mathrm{m})$ \\
\hline & 0.3 & 0.0444 & 17.76 & 0.0068 & 2.72 & 0.0203 & 8.12 \\
\hline \multirow[t]{5}{*}{ Sample } & 0.5 & 0.0372 & 14.88 & 0.0030 & 1.20 & 0.0104 & 4.16 \\
\hline & 0.8 & 0.0323 & 12.92 & 0.0012 & 0.48 & 0.0157 & 6.28 \\
\hline & 1.0 & 0.0308 & 12.32 & 0.0009 & 0.36 & 0.0130 & 5.20 \\
\hline & 1.5 & 0.0259 & 10.36 & - & - & 0.0057 & 2.28 \\
\hline & 2.0 & 0.0200 & 8.00 & - & - & - & - \\
\hline
\end{tabular}

Table 4. Resistance $(\Omega)$ and Conductivity (mho/m) of coupons in the various acids.

\begin{tabular}{ccccc}
\hline Sample & Nature of Coupon & Acid & Resistance $(\mathbf{\Omega})$ & Cond. $(\mathbf{m h o} / \mathbf{m})\left(\times \mathbf{1 0}^{-\mathbf{3}}\right)$ \\
\hline As-Received & - & 0.0466 & 18.64 \\
Uncoated & $\mathrm{HCl}$ & 0.0043 & 1.72 \\
Coated & $\mathrm{HCl}$ & 0.0155 & 6.20 \\
Uncoated & $\mathrm{HNO}_{3}$ & 0.0024 & 0.96 \\
Coated & $\mathrm{HNO}_{3}$ & 0.0092 & 3.68 \\
Uncoated & $\mathrm{HClO}_{4}$ & 0.0071 & 2.84 \\
Coated & $\mathrm{HClO}_{4}$ & 0.0114 & 4.56 \\
\hline
\end{tabular}

various acidic media. The conductivities of both the uncoated and coated coupons showed a remarkable deviation from those of the as-received samples.

This observation could be explained in terms of the dimensional changes which occurred during the corrosion process which in turn affects the properties of the metal. Similar observations were reported by Dawson and Turner [16]. The coated coupons had higher conductivity values (which means a decrease in resistivity) than the uncoated coupons. This is a further proof that the HPMP Inhibitor actually protected the metals from direct attack of the acids.

\section{Conclusion}

Based on the experimental results, it has been proven that HPMP is an effective inhibitor for high carbon steel in $\mathrm{HCI}, \mathrm{HNO}_{3}$ and $\mathrm{HClO}_{4}$ since it was able to protect the metal from the direct attack of the acids. This is evidenced by the higher conductivity values (which means lower resistivity values) recorded for the coated samples other than the samples not coated with HPMP.

\section{References}

[1] Dayton, M. (2012) High Carbon Steel—Properties and Uses. http://www.ehow.co.uk/list 7596348

[2] Oguzie, E.E., Li, Y. and Wang, F.H. (2007) Corrosion Inhibition and Adsorption Behavior of Methionine on Mild Steel in Sulphuric Acid and Synergistic Effect of Iodine Ion. Journal of Colloid and Interface Science, 310, 90-98. http://dx.doi.org/10.1016/j.jcis.2007.01.038

[3] Rahbar Ranji, A. and Zakeri, A.H. (2010) Mechanical Properties and Corrosion Resistance of Normal Strength and High Strength Steels in Chloride Solution. Journal of Naval Architecture and Marine Engineering, 7, 93-100.

[4] Rajappa, S.K., Venkatesha, T.V. and Praveen, B.M. (2008) Chemical Treatment of Zinc Surface and Its Corrosion Inhibition Studies. Bulletin of Materials Science, 31, 37-41. http://dx.doi.org/10.1007/s12034-008-0007-3 
[5] Abiola, O.K. and Oforka, N.C. (2002) Inhibition of the Corrosion of Mild Steel in Hydrochloric Acid by (4-Amino2-Methyl-5-pyrimidinyl methylthio) Acetic Acid and Precursor. Journal of Corrosion Science and Engineering, 3, 21.

[6] Gopiraman, M., Sathya, C., Vivekananthan, S., Kesavan, D. and Sulochana, N. (2011) Influence of 2,3-Dihydroxyflavanone on Corrosion Inhibition of Mild Steel in Acidic Medium. Journal of Materials Engineering and Performance, 21, 240-246. http://dx.doi.org/10.1007/s11665-011-9925-0

[7] Gopiraman, M., Sevakumara, N., Kesavan, D. and Karvemlu, R. (2012) Adsorption and Corrosion Inhibition Behaviour of N-(Phenylcarbamo-thioyl) Benzamide on Mild Steel in Acidic Medium. Progress in Organic Coatings, 73, 104-111. http://dx.doi.org/10.1016/j.porgcoat.2011.09.006

[8] Lavanya, M.N., Kesavan, D., Prahhavathi, N. and Julochana, N. (2009) Studies on Inhibitive Effect of 3-Hydroxyflavone on the Acid Corrosion of Mild Steel. Surface Review and Letters, 16, 845-853. http://dx.doi.org/10.1142/S0218625X09013396

[9] Abiola, O.K. and James, A.O. (2010) The Effects of Aloe Vera Extract on Corrosion and Kinetics of Corrosion Process on Zinc in HCI Solution. Corrosion Science, 52, 661-666. http://dx.doi.org/10.1016/j.corsci.2009.10.026

[10] Vogel, A.I. (1998) Text Book of Practical Organic Chemistry. 4th Edition, Longman Ltd., London, 882-889.

[11] Lee, J.D. (1996) Concise Inorganic Chemistry. 5th Edition, Chapman and Hall Ltd., London, 619-621.

[12] Owate, I.O., Abbey, T.M. and Imure, E.J. (1999) The Influence of Acidic Medium on some Electrical Properties of Copper Wire. NICA/ICOC/PAPR/99/15, 122-130.

[13] Brikby, I., Harrison, P. and Stevens, R. (1999) The Effect of Surface Transformation Due to Degradation. Journal of European society, 5, 37-46.

[14] Darry, P. and Spear, K. (1992) Corrosion of Materials in $\mathrm{N}_{2}$-H-CO. Journal of Corrosion Science, 75, 3257-3277.

[15] Abbey, T.M. and Obong, H.P. (2007) Corrosion Effects on the I-V Characteristics of Electrically Conducting Cables. Journal of Applied Sciences and Environmental Management, 11, 5-11.

[16] Dawson, J.L. and Turner, N.E.D. (1988) Corrosion Monitoring and Control. Journal Institute of Metals, 4, $218-222$. 
Scientific Research Publishing (SCIRP) is one of the largest Open Access journal publishers. It is currently publishing more than 200 open access, online, peer-reviewed journals covering a wide range of academic disciplines. SCIRP serves the worldwide academic communities and contributes to the progress and application of science with its publication.

Other selected journals from SCIRP are listed as below. Submit your manuscript to us via either submit@scirp.org or Online Submission Portal.
